\title{
Sensor Placement with Two-Dimensional Equal Arc Length Non-Uniform Sampling for Underwater Terrain Deformation Monitoring
}

\author{
Chunying $\mathrm{Xu}^{1,2,3, * \mathbb{D}}$, Junwei $\mathrm{Hu}^{3}$, Jiawang Chen ${ }^{3} \mathbb{D}$, Yongqiang $\mathrm{Ge}^{3}\left(\mathbb{D}\right.$ and Ruixin Liang ${ }^{1,2}$ \\ 1 College of Engineering, Shantou University, Shantou 515013, China; j490956099@163.com \\ 2 Guangdong Provincial Key Laboratory of Digital Signal and Image Processing, Shantou 515013, China \\ 3 Ocean Collage, Zhejiang University, Zhoushan 316021, China; jwhu@zju.edu.cn (J.H.); \\ arwang@zju.edu.cn (J.C.); ge_yongqiang@zju.edu.cn (Y.G.) \\ * Correspondence: chunyingxu@stu.edu.cn
}

check for updates

Citation: $\mathrm{Xu}, \mathrm{C} . ; \mathrm{Hu}$ J.; Chen, J.; Ge, Y.; Liang, R. Sensor Placement with Two-Dimensional Equal Arc Length Non-Uniform Sampling for Underwater Terrain Deformation Monitoring. J. Mar. Sci. Eng. 2021, 9 , 954. https://doi.org/10.3390/ jmse 9090954

Academic Editors: Cezary Specht, Adam Weintrit and Mariusz Specht

Received: 10 August 2021

Accepted: 29 August 2021

Published: 1 September 2021

Publisher's Note: MDPI stays neutral with regard to jurisdictional claims in published maps and institutional affiliations.

Copyright: (c) 2021 by the authors. Licensee MDPI, Basel, Switzerland. This article is an open access article distributed under the terms and conditions of the Creative Commons Attribution (CC BY) license (https:// creativecommons.org/licenses/by/ $4.0 /)$.

\begin{abstract}
Sensor placement plays an important role in terrain deformation monitoring systems and has an essential effect on data collection. The difficulty of sensor placement entails obtaining the most adequate and reliable information with the fewest number of sensors. Most sensor placement schemes are currently based on randomized non-uniform sampling and probability statistics, such as structural modality and optimization methods, which are difficult to directly apply due to the randomness and spatial heterogeneity of terrain deformation. In this study, the placement conditions of two-dimensional non-uniform sampling with equal arc length were deduced for underwater terrain deformation monitoring based on the MEMS accelerometer network. In order to completely reconstruct the underwater terrain, the arc length interval of the sensors should be less than $\frac{1}{2 \Omega}(\Omega$ is the maximum frequency of the detected terrain). The maximum MRE and maximum RMSE were both less than seven percent in a terrain deformation monitoring experiment and a water tank test. The research results help technicians apply contact sensor arrays for underwater terrain monitoring.
\end{abstract}

Keywords: sensor placement; underwater terrain monitoring; two-dimensional non-uniform sampling; equal arc length sampling; MEMS accelerometer sensor arrays

\section{Introduction \\ 1.1. Monitoring Methods for Underwater Terrain Deformation}

Underwater terrain monitoring is an important task in marine exploration and development. Monitoring the subsidence or uplift of underwater terrain provides early warning for the occurrence of underwater geological disasters [1,2]. For example, during the exploration and production of submarine gas hydrates, the decomposition of hydrates destroys the sediment structure and causes land subsidence, which may lead to geological disasters (e.g., collapse, landslides, and earthquakes) that endanger gas hydrate exploration [3].

The principal devices for underwater terrain surveys include single-beam $[4,5]$ and multi-beam sounding sonar [6-9] and contact sensor monitoring methods, such as fiber Bragg grating sensor arrays [10-12], MEMS sensor arrays [13-15], and optical fiber curvature sensors [16-18]. Contact sensor detection technology follows the movement or deformation of underwater terrain and is characterized by traceability, real-time capabilities, high precision, long duration, and continuous monitoring [11].

\subsection{Sensor Placement Schemes for Underwater Terrain Deformation}

Underwater terrain monitoring by contact sensor arrays is used to observe long-term terrain deformation. In contrast to static measurement, monitoring is a dynamic spatiotemporal process. Figure 1 shows that sensors 1-n are distributed in different spatial positions and contain positional information. Over time, the sampling values at different 
time points contain time information. Therefore, sampling both spatial and temporal domains should be considered in monitoring. Sampling in the spatial domain ensures that the terrain is collected and reconstructed without time distortion, whereas sampling in the time domain ensures the monitoring of changes in terrain deformation.

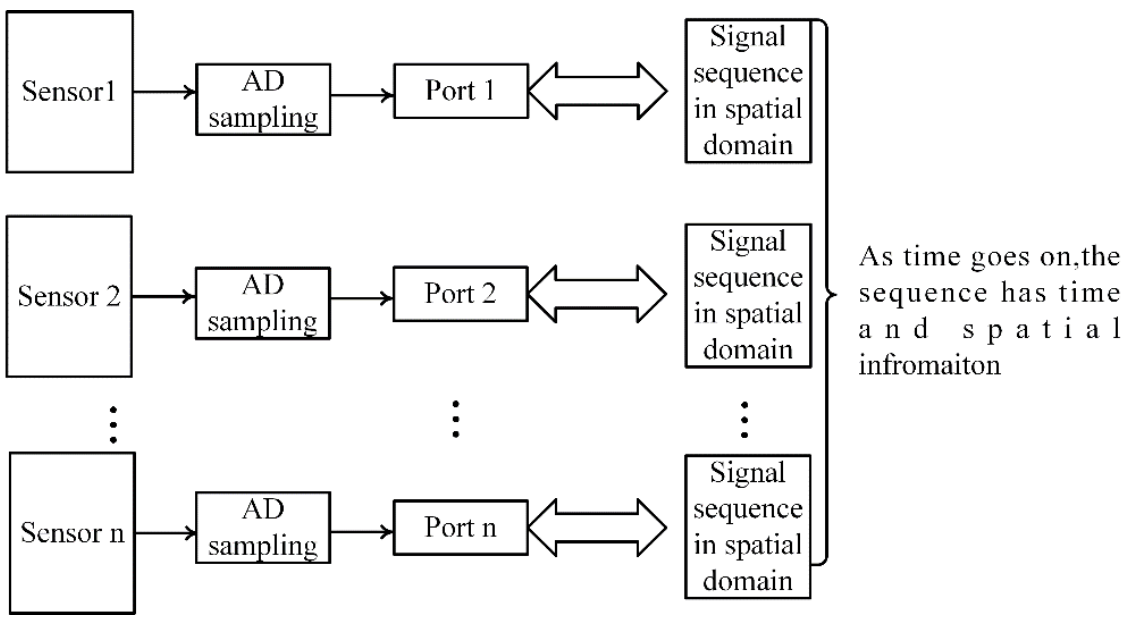

Figure 1. Signal collecting in the spatial and temporal domains.

Therefore, to measure and monitor changes in terrain deformation without distortion, the sensor distribution should meet spatial sampling theorem requirements; additionally, the acquisition frequency should meet time sampling theorem requirements. Terrain deformation is typically slow; therefore, spatial domain sampling should be emphasized.

In structural health monitoring, the sensor placement strategy is expressed as an optimization problem. The objective functions are based on the modal assurance criterion $[19,20]$, the probability of detection for maximizing the probability of damage detection or minimizing the false alarm rate [21], the mean squared error for estimating the structural parameter of interest (e.g., mode shape) [22], the multi-objective optimization problem [23], and solvers for the optimization problem (including the genetic and simulated annealing algorithms [24-26]). However, the methods based on structural modality and optimization are difficult to apply directly due to the randomness and spatial heterogeneity of terrain deformation.

In this study, MEMS accelerometer arrays (with an implicit equal and constant characteristic arc length interval of the sensors when the sensor array moves with the terrain) were used for underwater terrain monitoring [14]. Figure 2 shows that the sensor array was initially deployed in an equal arc interval; nonetheless, the sensor array sampling was non-uniform. For flat terrain, the spatial sampling was uniform, with equal intervals. For deformed terrain, the sensor array changes with the terrain; additionally, spatially uniform sampling becomes non-uniform sampling for equal arc length. In addition, non-uniform sampling with equal arc length has a smaller sampling interval and more sampling points for complicated terrain (longer arc length), a larger sampling interval, and fewer sampling points for simple terrain (shorter arc length). Thus, the sensor layout is adaptive.

The underwater terrain was monitored by sensor arrays, and the sampling was nonuniform and two-dimensional with equal arc length. Future studies should investigate whether the underwater terrain can be completely reconstructed and monitored with time changes from sampling sequences.

Previous studies address randomized non-uniform sampling [27-29] and periodic non-uniform sampling [30]. One-dimensional randomized non-uniform samples are often regarded as random perturbations from a uniform sampling grid in the analysis. Twodimensional randomized non-uniform samples only deviate from the uniform samples according to the following constraint: $\left|x_{n m}-n T\right|+\left|y_{n m}-m T\right| \leq(\log 2) / \pi$, where $x_{n m}$ and $y_{n m}$ are the horizontal and vertical coordinates of the samplers, respectively [31]. 


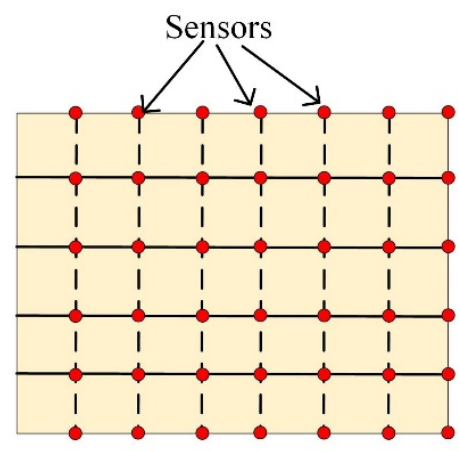

The terrain is flat

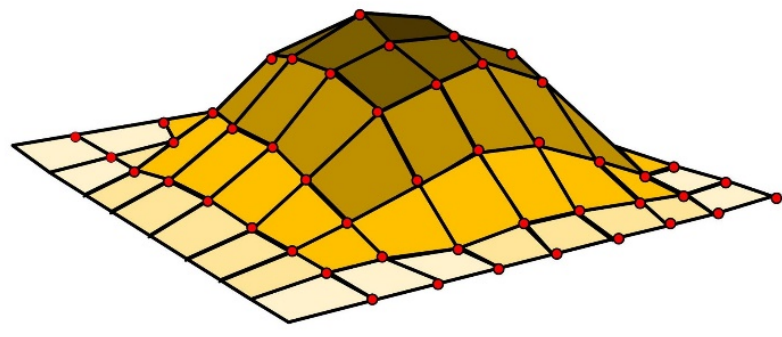

The terrain deforms

Figure 2. Two-dimensional non-uniform sampling with equal arc length.

For one-dimensional periodic non-uniform sampling, the samples and adjacent sampling points are not uniform; however, the interval of each sampling point and the subsequent $M$ th sampling point are equal. The sequence has a periodic structure with period $M$, where $M$ is an interval. For two-dimensional periodic non-uniform sampling, samples $\left\{x_{n}\right\}$ and $\left\{y_{m}\right\}$ are taken as two sets of independent periodic samplers. In other cases, the nonuniform samplers are on parallel lines denoted by $\left\{x_{n}\right\}$. The samplers on the lines are denoted by $\left\{y_{n m}\right\}$. The sampling set $\left\{x_{n}\right\}$ satisfies the one-dimensional condition $\left|x_{n}-n T\right| \leq T / 4$.

We studied one-dimensional non-uniform sampling for non-uniform sampling with equal arc lengths. General non-uniform spatial sampling requires the equal arc length interval of the sensor array to be less than $\frac{1}{4 \Omega}$. $\Omega$ is the maximum frequency of the detected object (baseband signal). Strictly increasing the sampling sequence requires the equal arc length interval of the sensor array to be less than $\frac{1}{2 \Omega}$. The sampling sequence strictly increases when the underwater terrain monitored does not include cliffs.

However, little research addresses two-dimensional non-uniform spatial sampling for contact sensor arrays with equal arc intervals. The arc length interval of sensors and the interval between sensor arrays are often set by experience. A greater number of sensors leads to higher accuracy. Dense sensor intervals are often required to completely monitor the underwater terrain. However, additional sensors increase the cost and the complexity of the system.

The exist sensor placement strategy based on structural modality and optimization in structural health monitoring is difficult to apply directly due to the randomness and spatial heterogeneity of terrain deformation. Therefore, in order to improve the accuracy and efficiency of the sensor array in terrain monitoring and reconstructing, achieve the optimal sensor array layout, use the least number of sensors to collect the most reliable and sufficient terrain information, and realize the reconstruction of the terrain without distortion. The research of the contact sensor array in submarine terrain monitoring was carried out, and the placement conditions of two-dimensional non-uniform sampling with equal arc length were deduced for underwater terrain deformation monitoring based on the MEMS accelerometer network.

In this study, we first investigate a mathematical model of two-dimensional uniform sampling. Second, we studied two-dimensional non-uniform spatial sampling with an equal arc interval and derived the condition of the non-uniform spatial sampling using the frame theorem. Finally, a terrain deformation simulation platform and monitoring test were designed to verify the correctness of the non-uniform spatial sampling condition, and a water tank test was conducted. 


\section{Two-Dimensional Non-Uniform Sampling Condition with Equal Arc Length}

\subsection{Mathematical Model of Two-Dimensional Uniform Sampling}

For a limited spatial frequency of the two-dimensional terrain $f(x, y), x \in[0, X], y \in$ $[0, Y]$, the spectrum $F(u, v)$ satisfies the following Equation (1):

$$
F(u, v)=\left\{\begin{array}{cl}
F(u, v) & |u| \leq \xi,|v| \leq \eta \\
0 & |u|>\xi,|v|>\eta
\end{array}\right.
$$

where $\xi$ and $\eta$ are the maximum spatial frequencies in the $u$ and $v$ directions, respectively. The sampling signal is the product of the original signal and the sampling function (twodimensional impulse string), as shown in Equation (2):

$$
\begin{gathered}
f_{S}(x, y)=f(x, y) \cdot S(x, y) \\
=\sum_{m=1}^{M} \sum_{n=1}^{N} f\left(x_{m n}, y_{m n}\right) \cdot \delta\left(x-x_{m n}, y-y_{m n}\right)
\end{gathered}
$$

where $m$ and $n$ are the sampling number in the $x$ and $y$ directions, respectively.

\subsection{Two-Dimensional Non-Uniform Sampling Condition with Equal Arc Length}

The spatial frequency space is $\Omega=[-\xi, \xi] \times[-\eta, \eta]$ ( $\xi$ and $\eta$ are the maximum spatial frequency in the $u$ and $v$ directions, respectively) in the two-dimensional non-uniform sampling. The sampling set $\left\{\left(x_{n}, y_{n m}\right)\right\}_{m, n \in \mathbb{Z}}$ increases monotonically and approaches positive or negative infinity $\left(\lim _{n \rightarrow \pm \infty} x_{n}= \pm \infty, \lim _{m, n \rightarrow \pm \infty} y_{n m}= \pm \infty, \sup _{n \in \mathbb{Z}}\left(x_{n+1}-x_{n}\right)=\delta_{x}\right.$ and $\left.\sup _{m, n \in \mathbb{Z}}\left(y_{n m+1}-y_{n m}\right)=\delta_{y}\right)$, where $\delta_{x}$ and $\delta_{y}$ satisfy Inequation (3); then, the original signal $m, n \in \mathbb{Z}$

can be reconstructed by the sampling point and sampling value set [30].

$$
\delta_{x}^{2} \xi^{2}+\delta_{y}^{2} \eta^{2}\left(1+2 \delta_{x} \xi\right)^{2}<\frac{1}{8} .
$$

According to Inequation (3), the sampling point set is divided by the $x$-axis (Figure 3). Moreover, the sampling point set should satisfy the condition that $\lim _{n \rightarrow \pm \infty} x_{n}= \pm \infty$, $\lim _{m, n \rightarrow \pm \infty} y_{n m}= \pm \infty$.Therefore, the sampling point set is limited and should be expanded (Equation (4)) to satisfy the condition of monotonic increase in the $x$ - and $y$-axis directions. Let $\widetilde{x}_{n}=x_{n}, \widetilde{y}_{n m}=y_{n m}$, and $f\left(\widetilde{x}_{n}, \widetilde{y}_{n m}\right)=f\left(x_{n}, y_{n m}\right)$ remain unchanged for the sampling points and values. In other cases, $\widetilde{x}_{n+1}-\widetilde{x}_{n}=\Delta x>0, \widetilde{y}_{n m}-\widetilde{y}_{n m-1}=\Delta y>0$, and $f\left(\widetilde{x}_{n}, \widetilde{y}_{n m}\right)=0$. The expanded points increase monotonically. The sampling values are zero, non-increasing, or decreasing with reference to the initial sample signal.

$$
\begin{gathered}
\left(\widetilde{x}_{n}, \widetilde{y}_{n m}\right)=\left\{\begin{array}{c}
\left(x_{1}-(1-n) \Delta x, \quad y_{n 1}-(1-m) \Delta y\right), m \in[-\infty, 0] \text { or } n \in[-\infty, 0] \\
\left(x_{n}, y_{n m}\right), m \in[1, M], n \in[1, N] \\
\left(x_{1}+(n-N) \Delta x, y_{n 1}+(m-M) \Delta y\right), m \in[M+1, \infty] \text { or } n \in[N+1, \infty]
\end{array}\right. \\
f\left(\widetilde{x}_{n}, \widetilde{y}_{n m}\right)=\left\{\begin{array}{c}
0, \quad m \in[-\infty, 0] \text { or } n \in[-\infty, 0] \\
f\left(x_{n}, y_{n m}\right), \quad m \in[1, M], n \in[1, N] \\
0, \quad m \in[M+1, \infty] \text { or } n \in[N+1, \infty]
\end{array}\right.
\end{gathered}
$$




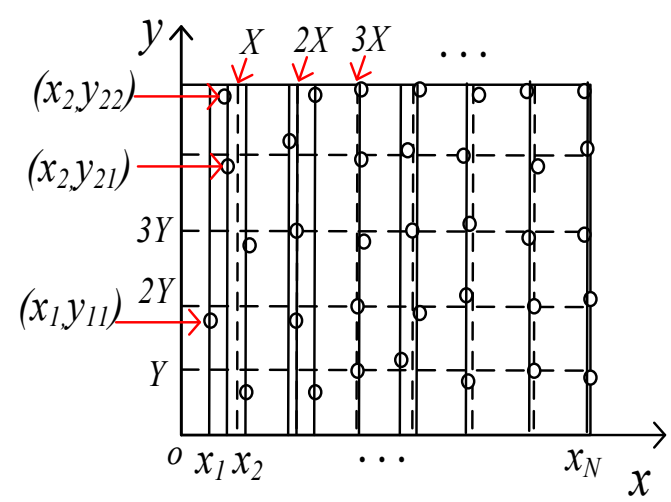

Figure 3. Sampling point division.

The expanded sampling point set satisfies the conditions of monotonic increase and approaches positive or negative infinity. Let $0<\Delta x \leq \delta_{x}$ and $0<\Delta y \leq \delta_{y}$; if $\delta_{x}$ and $\delta_{y}$ satisfy the condition $\delta_{x}^{2} \xi^{2}+\delta_{y}^{2} \eta^{2}\left(1+2 \delta_{x} \xi\right)^{2}<\frac{1}{8}$, then the theorem is satisfied. To obtain the maximum sampling interval, let $\lambda=\min \{\xi, \eta\}$; then, Inequation (3) can be transformed into Equation (5):

$$
\delta_{x}^{2}+\delta_{y}^{2}\left(1+2 \delta_{x} \lambda\right)^{2}<\frac{1}{8 \lambda^{2}}
$$

If the maximum frequency of the underwater terrain is known, $\lambda$ is known, and the sampling interval $\delta_{x}$ and $\delta_{y}$ can be obtained according to Equation (5). However, Equation (5) shows that the sampling density will be large; thus, the following nonuniform sampling theorem is used in this study.

In another theorem [31], $f(x, y)$ is a band-limited function in space $\varepsilon_{R}\left(f(x, y) \in \varepsilon_{R}\right)$. $\varepsilon_{R}$ is defined as $\varepsilon_{R}=\left\{f \in L^{2}\left(\mathbb{R}^{2}\right): F(u, v)=0\right.$, when $\left.u^{2}+v^{2} \geq R^{2}\right\}$. Assuming that the sampling set $\left\{\left(x_{i}, y_{i}\right)\right\}_{i \in I}$ satisfies $\inf _{i \neq k}\left[\left(x_{i}-x_{k}\right)^{2}+\left(y_{i}-y_{k}\right)^{2}\right]>0$ and $\cup_{i \in I} B_{r}\left(x_{i}, y_{i}\right)$ $=\mathbb{R}^{2}$ (the maximum distance between sampling points $\left(x_{i}, y_{i}\right)$ and $\left(x_{k}, y_{k}\right)$ is $2 r$, where $k \neq i$ ). If $r R<\frac{1}{4}$, then frame bounds $A, B>0$ exist, such that the frame Inequalities (6) hold for all $f \in \varepsilon_{R}$.

$$
A \int_{\mathbb{R}} \int_{\mathbb{R}}|f(x, y)|^{2} d x d y \leq \sum_{i \in I}|f(x, y)|^{2} \leq B \int_{\mathbb{R}} \int_{\mathbb{R}}|f(x, y)|^{2} d x d y
$$

For application, the maximum frequencies of different shapes of underwater terrain are different. The amplitude frequency for different underwater terrain shapes is assumed to be within $\varepsilon_{R}$. $\xi$ and $\eta$ are assumed to be the maximum spatial frequencies in the $u$ and $v$ directions, respectively. Thus, the maximum frequency is $R=\max \{\xi, \eta\}$. From this relationship $r R<\frac{1}{4}$, and the distance between sampling points $2 r$ can be obtained.

\section{Terrain Deformation Simulation Experiment}

\subsection{Experiment Design}

The experimental platform primarily includes a terrain deformation simulation system, a three-dimensional (3D) laser scanner, a sensor array, and a computer for data processing and terrain display (Figure 4). Terrain deformation is simulated by the platform, which measures $1.8 \times 2.1 \mathrm{~m}$ (the length along the sensor array is $2.1 \mathrm{~m}$, and the length in the direction perpendicular to the sensor array is $1.8 \mathrm{~m})$. Sixteen $(4 \times 4)$ screw slides were placed in the area. The distances between the screw slides were 70 and $0.45 \mathrm{~cm}$. The height of the screw slides was controlled by the motors. The shape of the terrain was constructed by the different heights of the screw slides. 


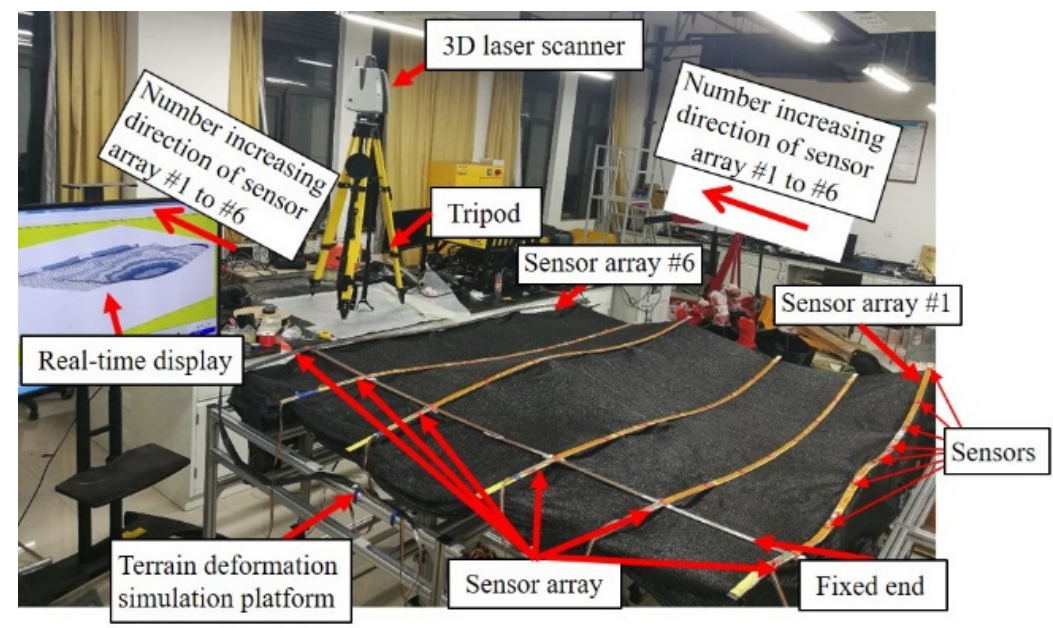

Figure 4. Simulation terrain shape \#1.

The terrain surface was simulated using an elastic black net with correlation and heterogeneity that simulates the terrain characteristics well. The adjacent area of the net was deformed by the movement of the screws. The amount of deformation decreased with distance from the screws, thus characterizing the correction. Heterogeneity indicates that the movement of a screw cannot cause the movement of all points in the net. The range of the influence of screw movement was limited.

The terrain data were obtained by the 3D laser scanner, which was used as the real value of the terrain. The accuracy of the 3D laser scanner was $3 \mathrm{~mm}$. Six sensor arrays (Figure 4) were arranged on the net, and one end was fixed. Each sensor array (with a length of $2.1 \mathrm{~m}$ ) sensed the tilt angles of the terrain and collected and processed data; the results were displayed on a computer [14].

The 3D laser scanned the terrain and obtained the point cloud data, which were processed by the Cyclone software through point cloud data simplification, segmentation, and coordinate extraction. In this study, we constructed three different terrain shapes.

The terrain data were extracted in equal intervals of $0.02 \mathrm{~m}$ along the $x$-axis (along the direction of the length of the sensor array) and $y$-axis (perpendicular to the direction of the $x$-axis) directions. The number of samples in the $x$-axis direction was 105, and the number of samples in the $y$-axis direction was 90 . The two-dimensional amplitude spectrum was calculated using Equation (7):

$$
F(u, v)=\sum_{x=0}^{M-1} \sum_{y=0}^{N-1} f(x, y) e^{-j 2 \pi(u x / M+v y / N)} .
$$

where $f(x, y)$ are the points of underwater terrain; and $M$ and $N$ are the number of samples in the $x$ - and $y$-axis directions, respectively. $M$ is 105 and $N$ is $90 ; u$ and $v$ are discrete variables $(u=0,1,2, \ldots, M-1$ and $\mathrm{v}=0,1,2, \ldots, N-1)$, respectively. The amplitude $|F(u, v)|$ is the two-dimensional amplitude spectrum of the underwater terrain [32]. The amplitude frequency resolution ( $\Delta u$ and $\Delta v$ ) of the terrain is inversely proportional to the interval of the 1 sample points and the number of samples, as shown in Equation (8):

$$
\left\{\begin{array}{rl}
\Delta u & =\frac{1}{M \Delta x} \\
\Delta v & =\frac{1}{N \Delta y}
\end{array} .\right.
$$

where $\Delta x$ and $\Delta y$ are the intervals of the sampling points. The amplitude frequency resolutions $\Delta u \approx 0.47 \mathrm{~m}^{-1}$ and $\Delta v \approx 0.55 \mathrm{~m}^{-1}$.

Figures 5-7 show the two-dimensional amplitude spectra of the three shapes and the partial enlargement chart. The $\mathrm{z}$ axis represents the relative amplitude of $|F(u, v)|$. Figures $5-7$ show that the principal frequency of the terrain is concentrated in the low- 
frequency region. The relative amplitude approaches zero (on the order of $10^{-5}$ ) at frequencies of $u>0$ and $v>0$, and is close to zero when $u \neq 0$ and $v \neq 0$. The amplitude spectrum of the underwater terrain is $[-\xi, \xi] \times[-\eta, \eta]$ and rectangular; $\xi$ and $\eta$ are the maximum frequencies in the $u$ and $v$ directions.
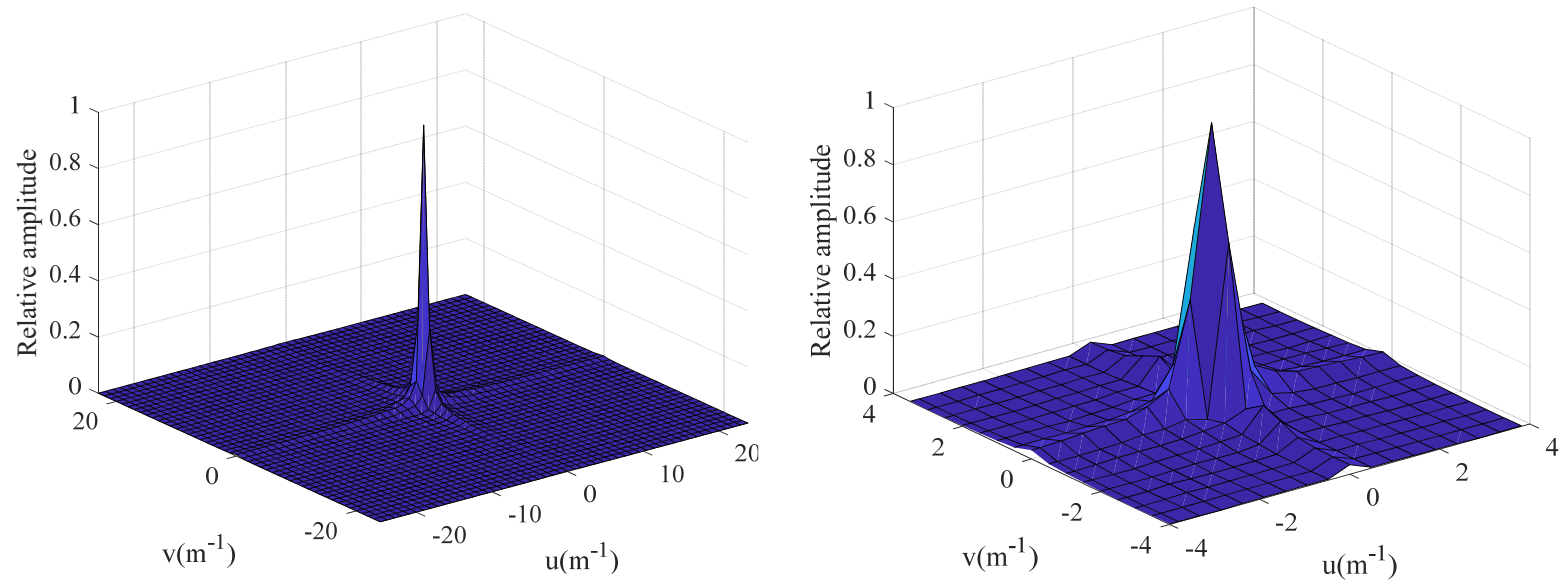

Figure 5. Two-dimensional amplitude spectrum of shape \#1-1. Full graph (left), partial enlargement graph (right).
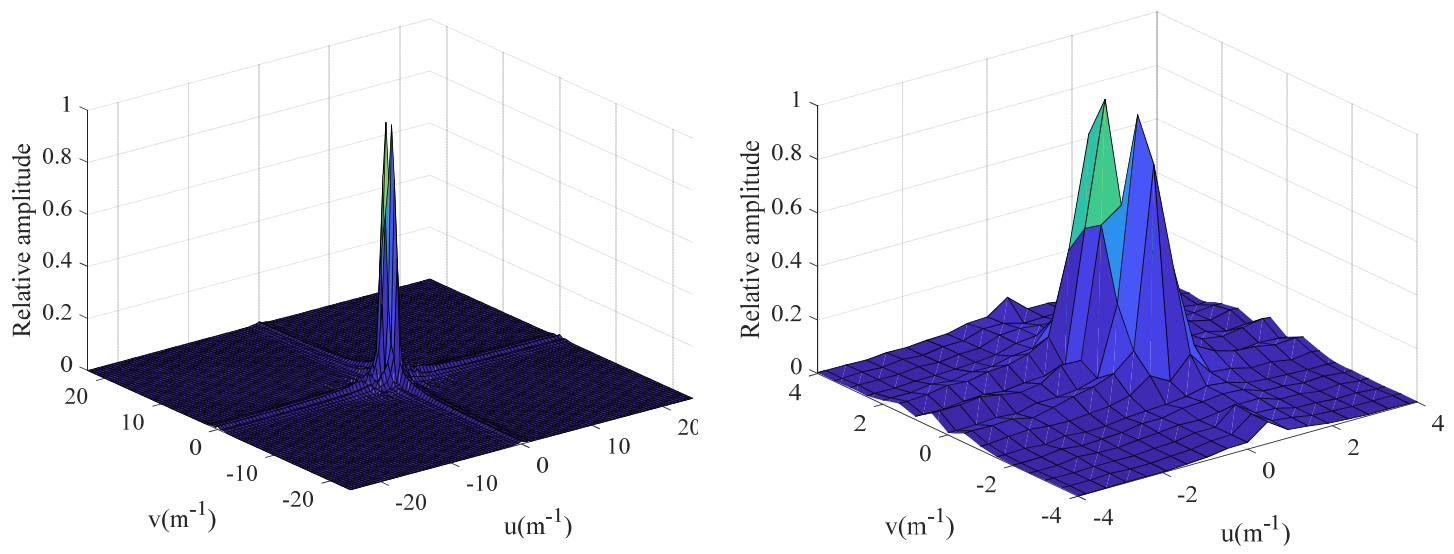

Figure 6. Two-dimensional amplitude spectrum of shape \#1-2. Full graph (left), partial enlargement graph (right).
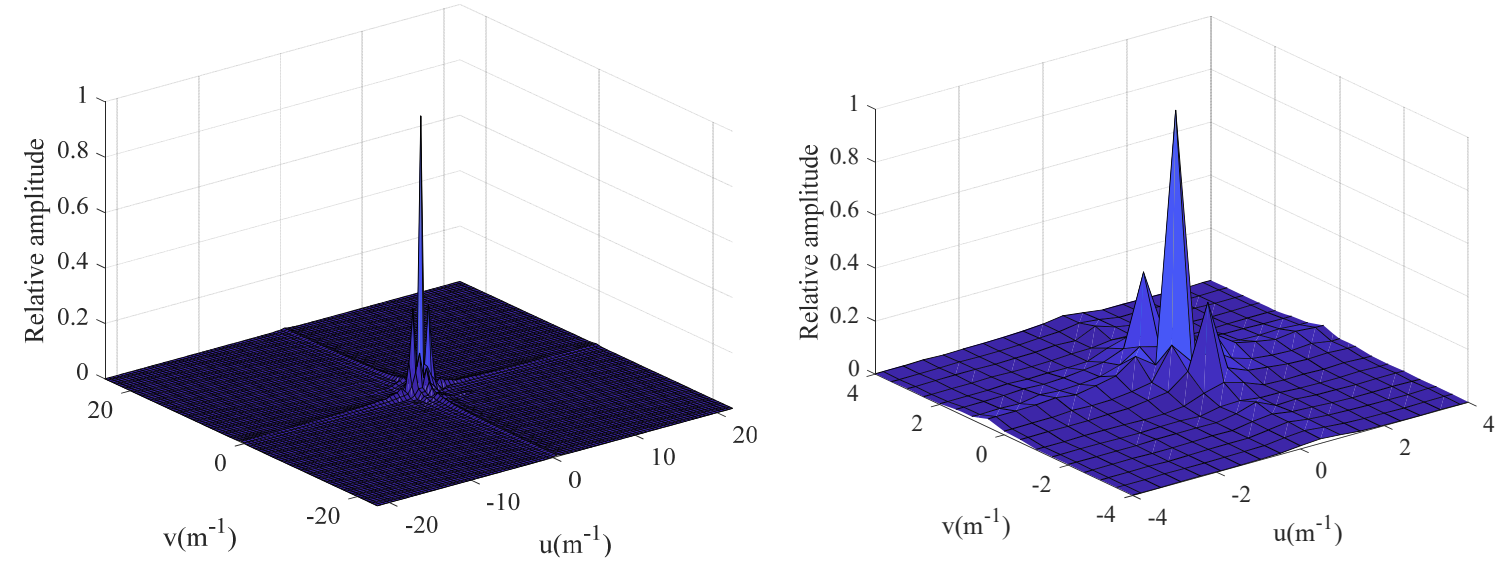

Figure 7. The two-dimensional amplitude spectrum of shape \#1-3. Full graph (left), partial enlargement graph (right).

Assuming $\xi \geq \eta$, let $R=\max \{\xi, \eta\}$. Figure 8 shows the relationship between the rectangular and circular frequency ranges. The underwater terrain is a band-limited function in space $\varepsilon_{\Omega}$ that is $f(x, y) \in \varepsilon_{\Omega}, \varepsilon_{\Omega}=\left\{f \in L^{2}\left(\mathbb{R}^{2}\right): F(u, v)=0\right.$, when $\left.u^{2}+v^{2} \geq R^{2}\right\}$. 
The sampling point set $\left\{\left(x_{i}, y_{i}\right)\right\}_{i \in I}$ satisfies $\inf _{i \neq k}\left[\left(x_{i}-x_{k}\right)^{2}+\left(y_{i}-y_{k}\right)^{2}\right]>0$ when the monitored terrain does not include a cliff. Moreover, the maximum arc-length interval between the sampling points is $2 r<\frac{1}{2 R}$. Therefore, both the arc-length intervals of sensors in the array and among the sensor arrays are less than $\frac{1}{2 R}$; additionally, the interval between all sampling points is less than $\frac{1}{2 R}$, where $R=\xi$.

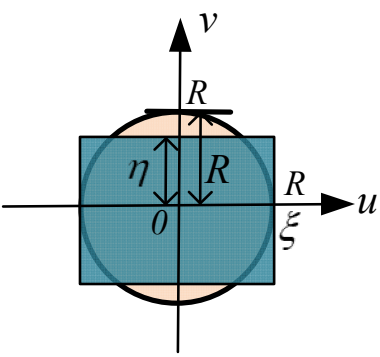

Figure 8. Relationship between the rectangular and circular frequency ranges.

Because the underwater terrain range is limited, the amplitude spectrum is unlimited. The highest frequency in this study is the frequency at which the 95\% energy is concentrated. Table 1 lists the highest frequency of the terrain: $\xi=u_{\max }=1.41 \mathrm{~m}^{-1}$ and $\eta=v_{\max }$ $=1.10 \mathrm{~m}^{-1}$. Figures 5 and 7 (shapes \#1-1 and \#1-3) show the peak at $(0,0)$ with a relative amplitude of 1 . Thus, the major frequencies of shapes \#1-1 and \#1-3 were (0,0). Shape \#1-2 has peaks at $(0,0.55)$ and $(0,-0.55)$ (Figure 7$)$. The frequency distribution is symmetrical. Therefore, the main frequency of the terrain from \#1-2 is $(0,0.55)$.

Table 1. The highest frequency of the terrain.

\begin{tabular}{cccc}
\hline & Shape \#1-1 & Shape \#1-2 & Shape \#1-3 \\
\hline $\begin{array}{c}\text { Highest frequency }(u, \\
v)\left(\mathrm{m}^{-1}\right)\end{array}$ & $(0.94,1.10)$ & $(1.41,1.10)$ & $(0.94,1.10)$ \\
\hline
\end{tabular}

Therefore, $R=\max \{\xi, \eta\}=1.41 \mathrm{~m}^{-1}$. According to the sampling theorem, the interval between the sensors should be less than $\frac{1}{2 R} \approx 0.35 \mathrm{~m}$. The length of the sensor array is $2.1 \mathrm{~m}$. The amplitude frequencies with different shapes were assumed to be less than $1.41 \mathrm{~m}^{-1}$. Each array contains seven sensors, and the arc-length interval between sensors is 0.30 .

\subsection{Experimental Results}

The three shapes were tested to verify non-uniform sampling with equal arc length. We assumed that the amplitude frequencies with different shapes were within the highest above-obtained frequency range. The terrain coordinates were calculated by MATLAB according to reference [14]. Forty-two coordinates were used to analyze the monitoring error. Table 2 lists the statistical errors monitored by the sensor array system. The deformation amount was the relative value of the fixed end.

Table 2. Terrain simulation monitoring error statistics.

\begin{tabular}{cccc}
\hline & Shape \#1-1 & Shape \#1-2 & Shape \#1-3 \\
\hline Mean absolute error & 1.12 & 0.97 & 1.09 \\
$(\mathrm{~cm})$ & 6.47 & 6.87 & 5.09 \\
MRE $(\%)$ & 6.01 & 5.53 & 4.43 \\
\hline RRMSE (\%) & & .43 & \\
\hline
\end{tabular}

Figures 9 and 10 and Table 2 show that the reconstructed terrain shape is basically consistent with the actual shape. Table 2 shows the calculated relative root-mean-square 
error (RRMSE) and mean relative error (MRE) between the original and reconstructed signals and the strong agreement between the data from the sensor array and the data from the 3D laser scanner. The maximum MRE was 6.87\% (shape \#1-2). The maximum RRMSE was $6.01 \%$ (shape \#1-1).

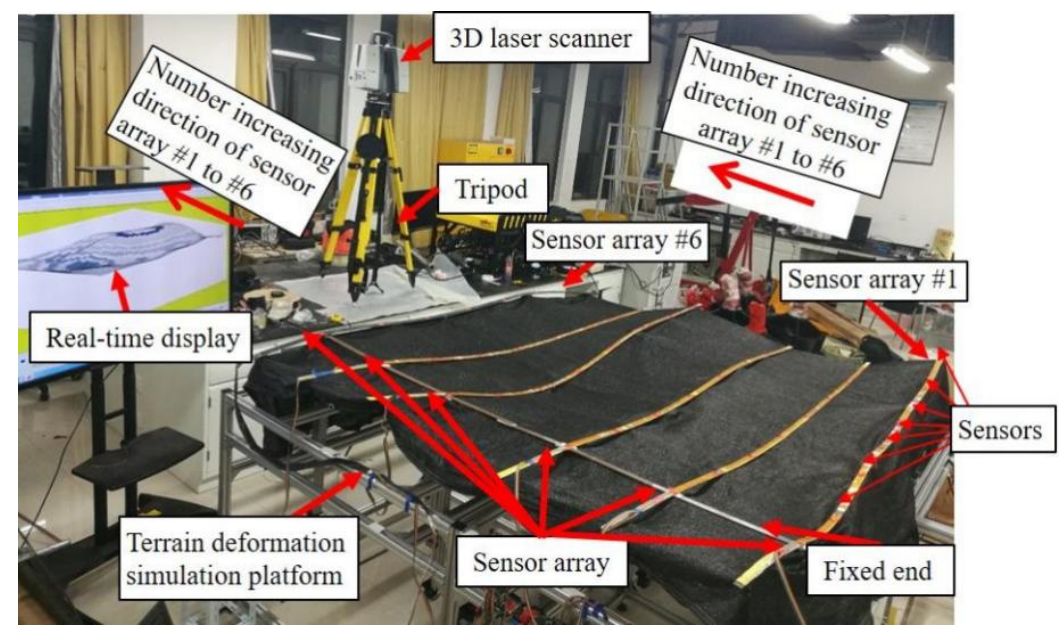

Figure 9. Terrain shape \#1-2.

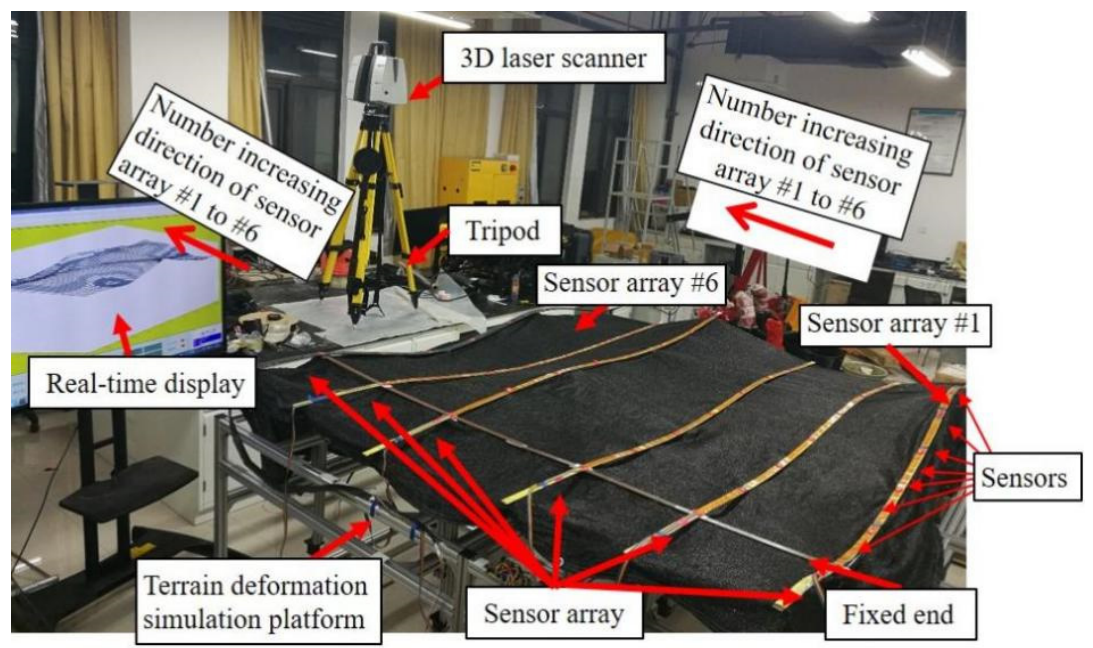

Figure 10. Terrain shape \#1-3.

The errors have three primary causes. First, the terrain monitoring range was limited; further, energy loss in the calculation of the highest frequency caused reconstruction error. Second, according to the sensor datasheet, the angle error obtained by the MEMS accelerometer was $0.1^{\circ}$. The arc length interval was $0.30 \mathrm{~m}$. The error was $0.05 \mathrm{~cm}$, and the maximum mean absolute error as $1.12 \mathrm{~cm}$. Therefore, the angle error of the sensor was greater than $4.5 \%$. Third, the sensors do not fit the moving terrain surface well, possibly increasing the angle measurement error.

\section{A Water Tank Experiment}

\subsection{Experiment Design}

A sand bed was laid in a water tank to simulate underwater terrain. Figure 11 shows that an ultrasonic monitoring system was adopted to measure the shape of the sand bed (which was alternatively manually measured). The ultrasonic measuring system is a commercial product from the company SINFOTEK (China). The ultrasonic measurement system included a three-dimensional guide rail and an ultrasonic displacement sensor. The ultrasonic sensor measures the height with an accuracy of $\pm 0.1 \mathrm{~cm}$, which is the 
z-coordinate value in this study. The corresponding software system included a server and client that achieves basic data service and visualizes the surface reconstruction of the sand bed, respectively. The position and running speed of the gauging vehicle were set using upper computer software. The sampling interval was set to $1 \mathrm{~cm}$. In every sampling position, the vehicle stopped for $1 \mathrm{~s}$ for multiple data collection; the average value was taken as the data at the current position.

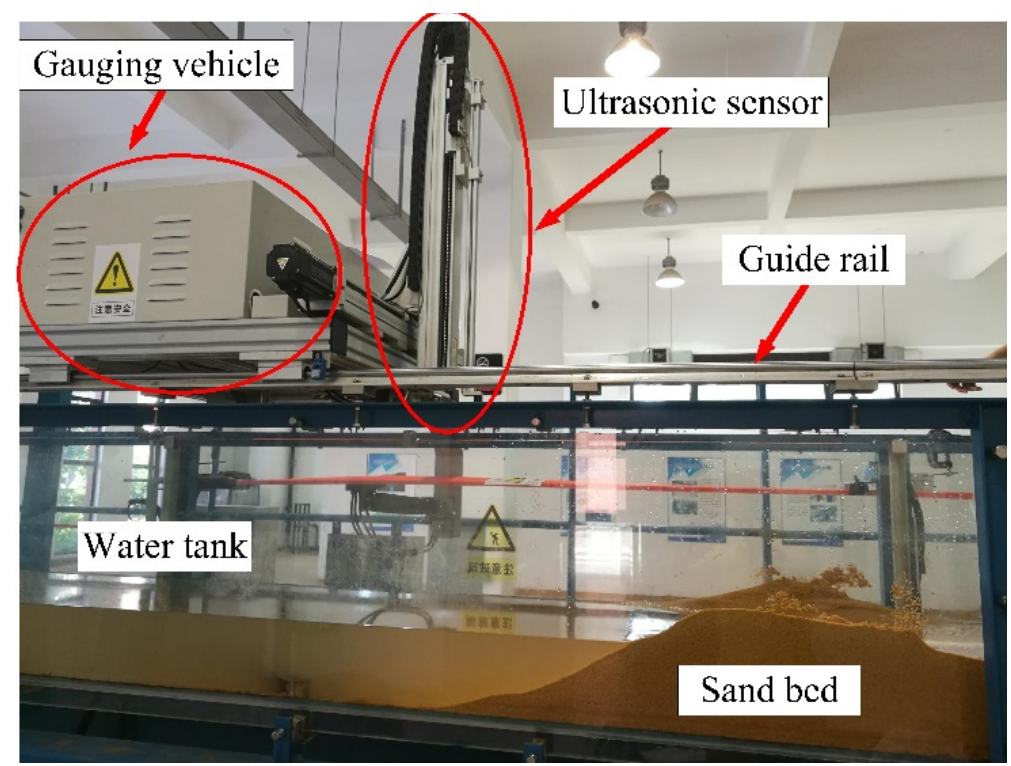

Figure 11. Water tank and ultrasonic measuring system.

The sand bed measured $40 \mathrm{~cm} \times 80 \mathrm{~cm}$. Three sand bed shapes were constructed (Figures 12-14). The sand bed data were collected using an ultrasonic measuring system.

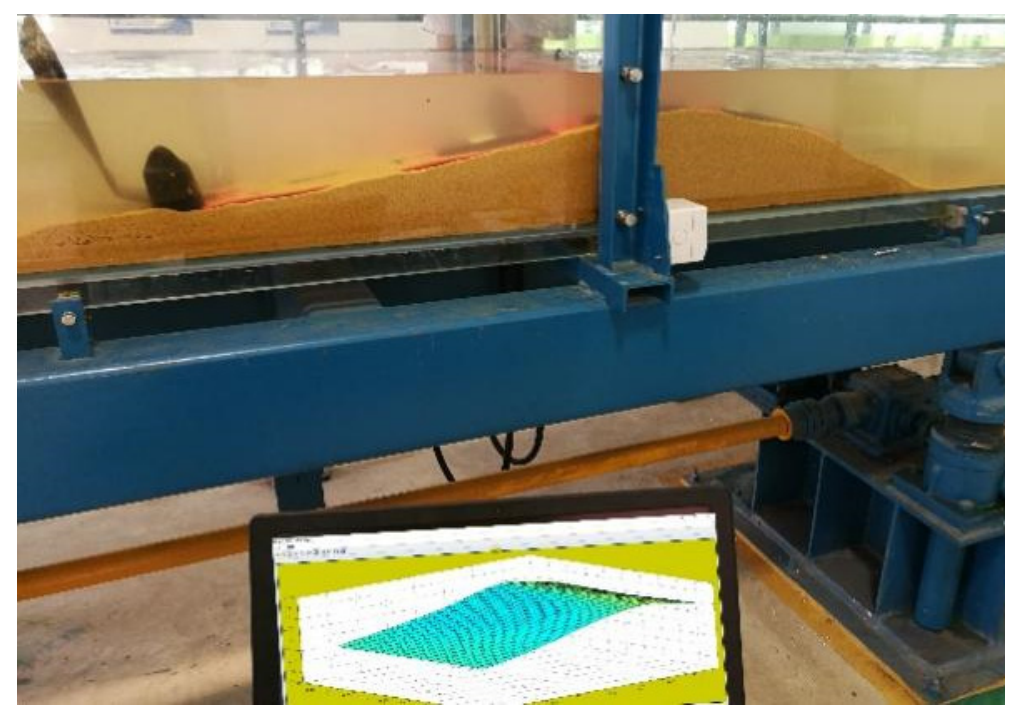

Figure 12. Sand bed shape \#2-1. 


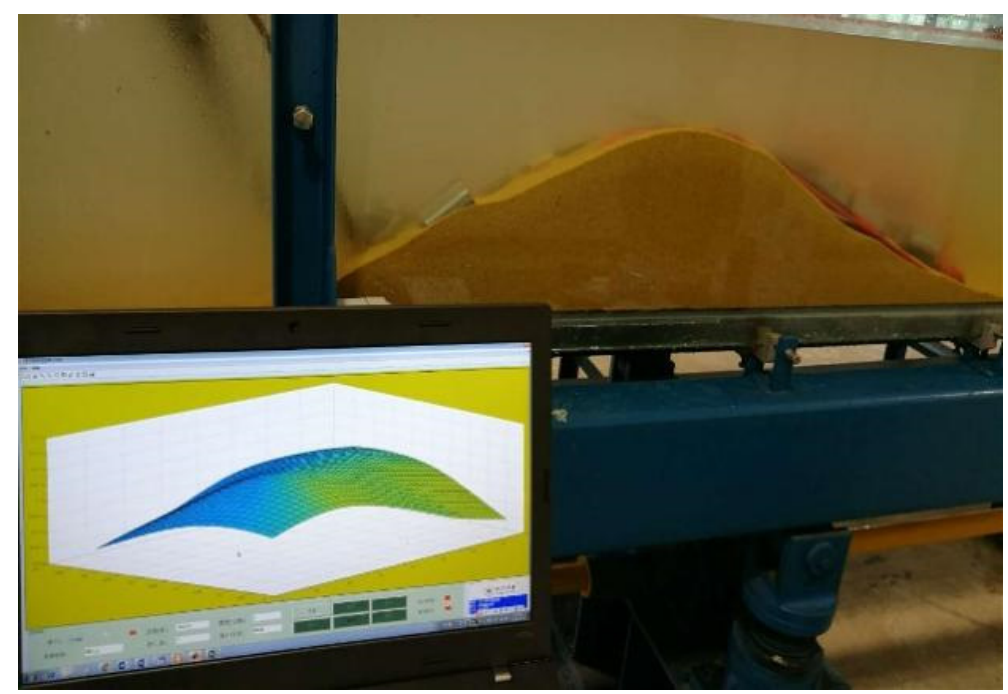

Figure 13. Sand bed shape \#2-3.

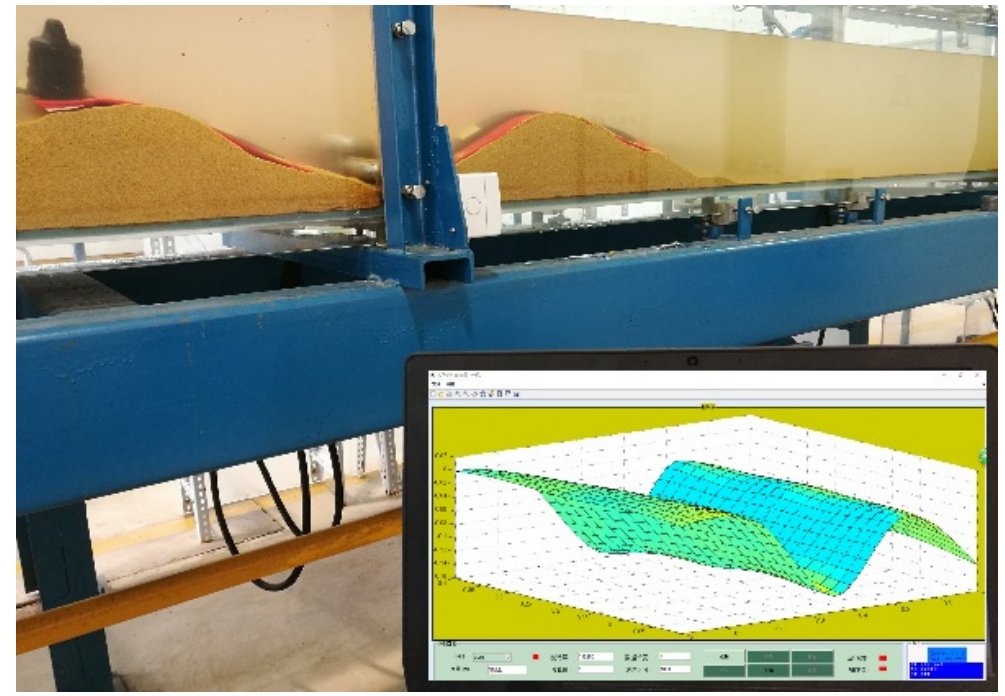

Figure 14. Sand bed shape \#2-4.

The sand bed data were collected at equal intervals of $0.01 \mathrm{~m}$ in the $x$-and $y$-axis directions. The number of samples in the $x$-axis and $y$-axis directions were 80 and 40, respectively. The two-dimensional amplitude spectrum was calculated using Equation (6). According to Equation (7), the amplitude frequency resolution was $\Delta u=1.25 \mathrm{~m}^{-1}$ and $\Delta v=2.5 \mathrm{~m}^{-1}$. The area of the sand bed is small; thus, the amplitude frequency resolution is low, especially in the $v$ direction.

Figures 15-17 show the two-dimensional amplitude spectrum of the three shapes. The frequency of the sand beds was concentrated in the low-frequency region, with a peak at $(0,0)$ (Figures 18-21). The principal frequency of the sand bed was $(0,0)$. Table 3 shows the two-dimensional frequency amplitude of the sand bed. The highest frequencies were $\xi=u_{\max }=2.5 \mathrm{~m}^{-1}$ and $\eta=v_{\max }=2.5 \mathrm{~m}^{-1}$. Therefore, $R=\max \{\xi, \eta\}=2.5 \mathrm{~m}^{-1}$. The sampling theorem states that the interval between the sensors should be less than $\frac{1}{2 R} \approx 0.2 \mathrm{~m}$. The amplitude frequency resolution was low; therefore, the arc length interval was set as 0.2. 


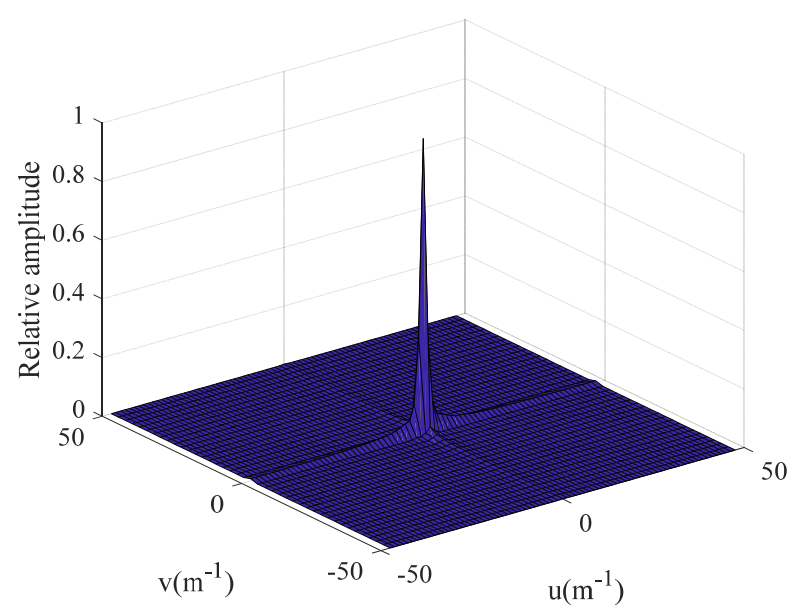

Figure 15. Two-dimensional amplitude spectrum of Shape \#2-1.

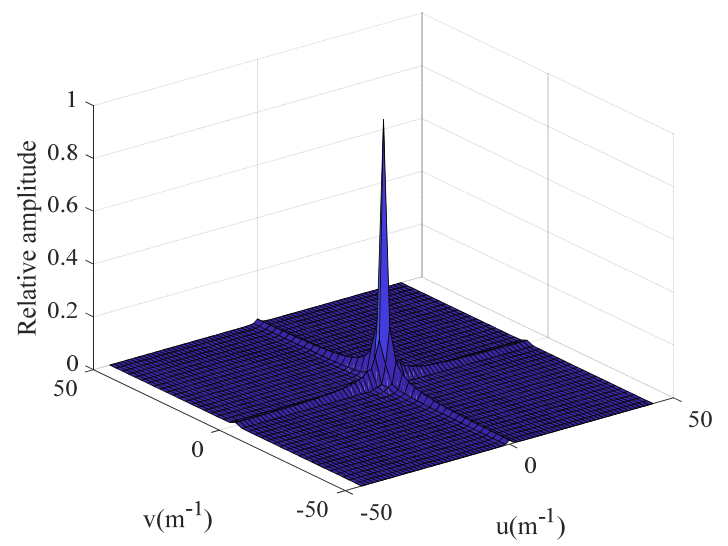

Figure 16. Two-dimensional amplitude spectrum of Shape \#2-2.

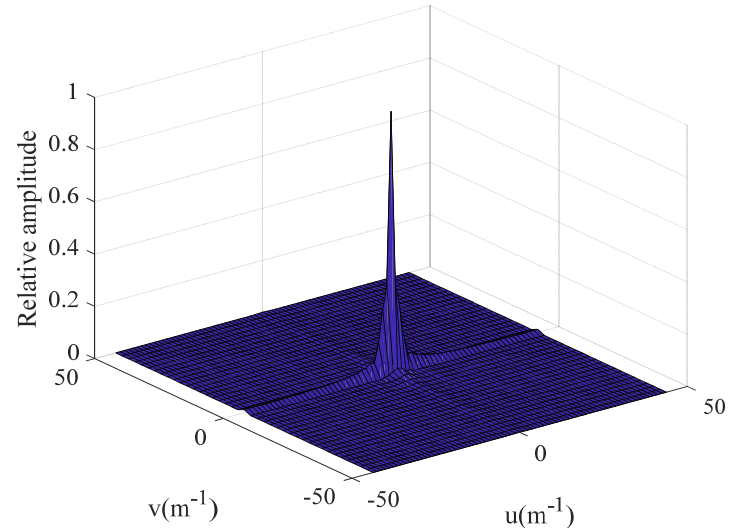

Figure 17. Two-dimensional amplitude spectrum of Shape \#2-3. 

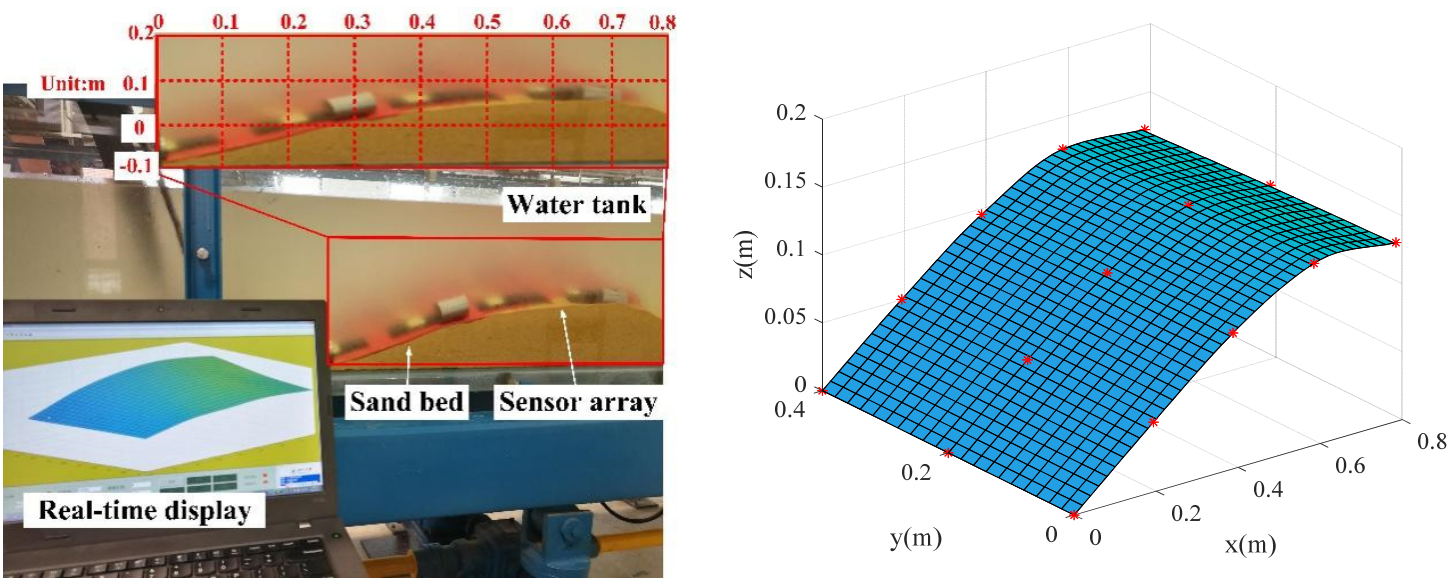

Figure 18. Shape \#2-1. Sand bed (left), reconstruction graph (right).
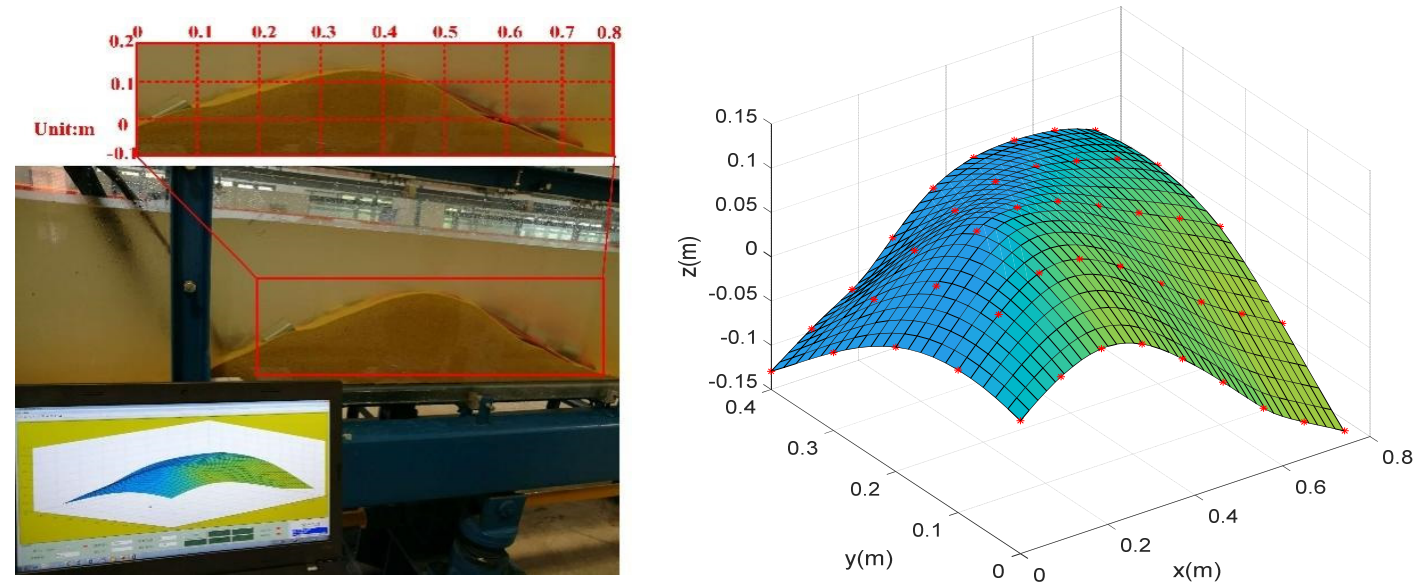

Figure 19. Shape \#2-2. Sand bed (left), reconstruction graph (right).
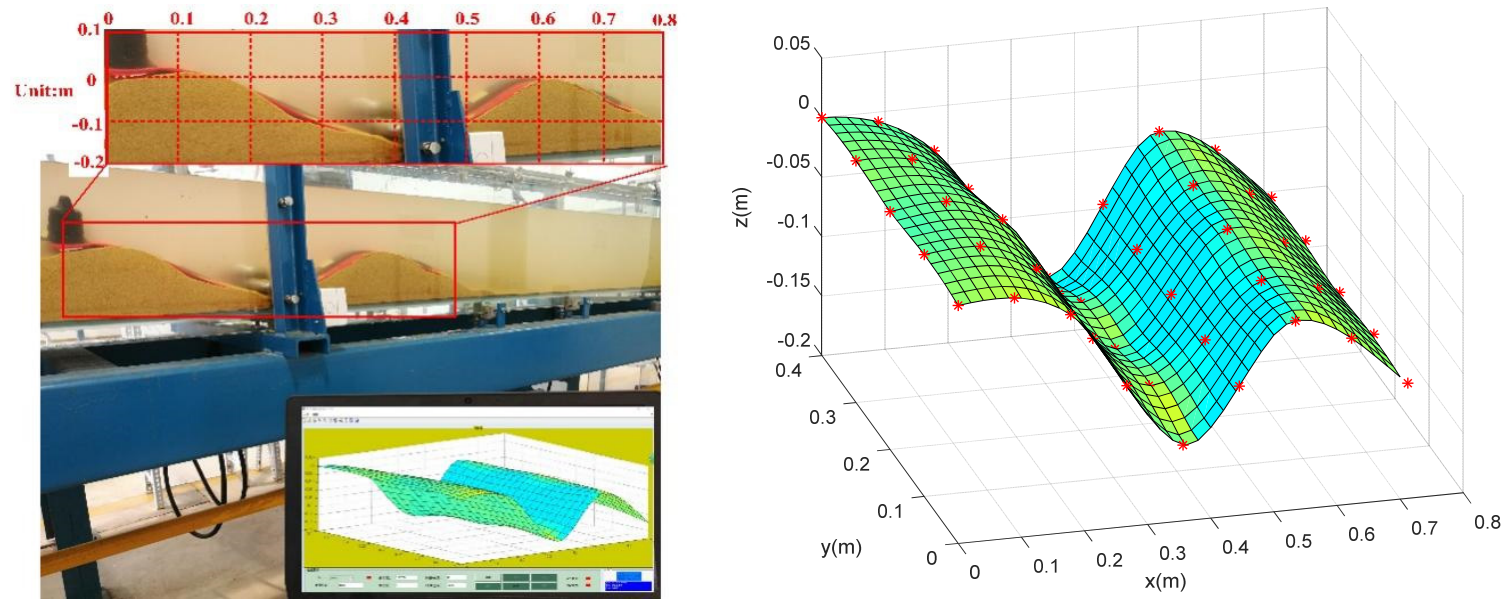

Figure 20. Shape \#2-3. Sand bed (left), reconstruction graph (right). 

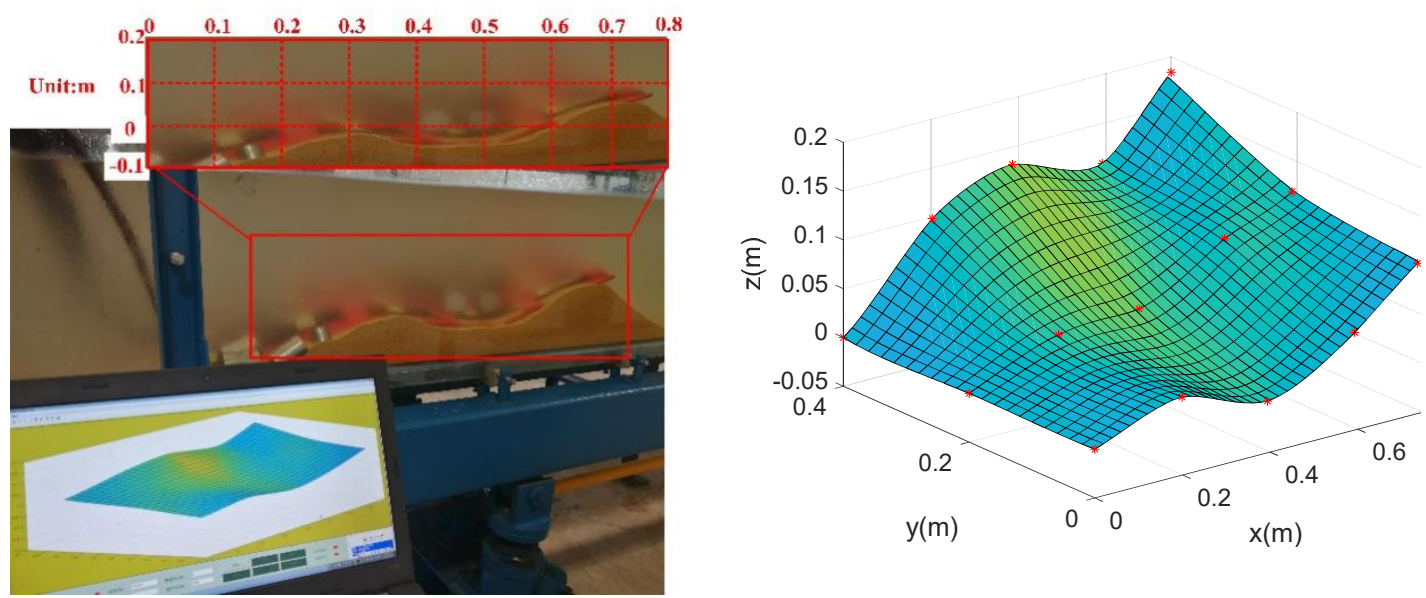

Figure 21. Shape \#2-4. Sand bed (left), reconstruction graph (right).

Table 3. Highest sand bed frequency.

\begin{tabular}{cccc}
\hline & Shape \#2-1 & Shape \#2-2 & Shape \#2-3 \\
\hline $\begin{array}{c}\text { Highest frequency }(u, \\
v)\left(\mathrm{m}^{-1}\right)\end{array}$ & $(1.25,2.5)$ & $(2.5,2.5)$ & $(1.25,2.5)$ \\
\hline
\end{tabular}

\subsection{Experimental Results}

The five shapes (including Shape \#2-4 and Shape \#2-5) of the sand bed were tested to verify the non-uniform sampling with equal arc length. We assumed that the amplitude frequencies of the sand bed with different shapes were within the highest aboveobtained frequency range. The sensor arrays measured the attitude angles of the sand beds. The shapes of the sand bed were reconstructed using a reconstruction algorithm [14,15] (Figures 18-22). The RRMSE and MRE between the original and reconstructed signals were also calculated (Table 4).
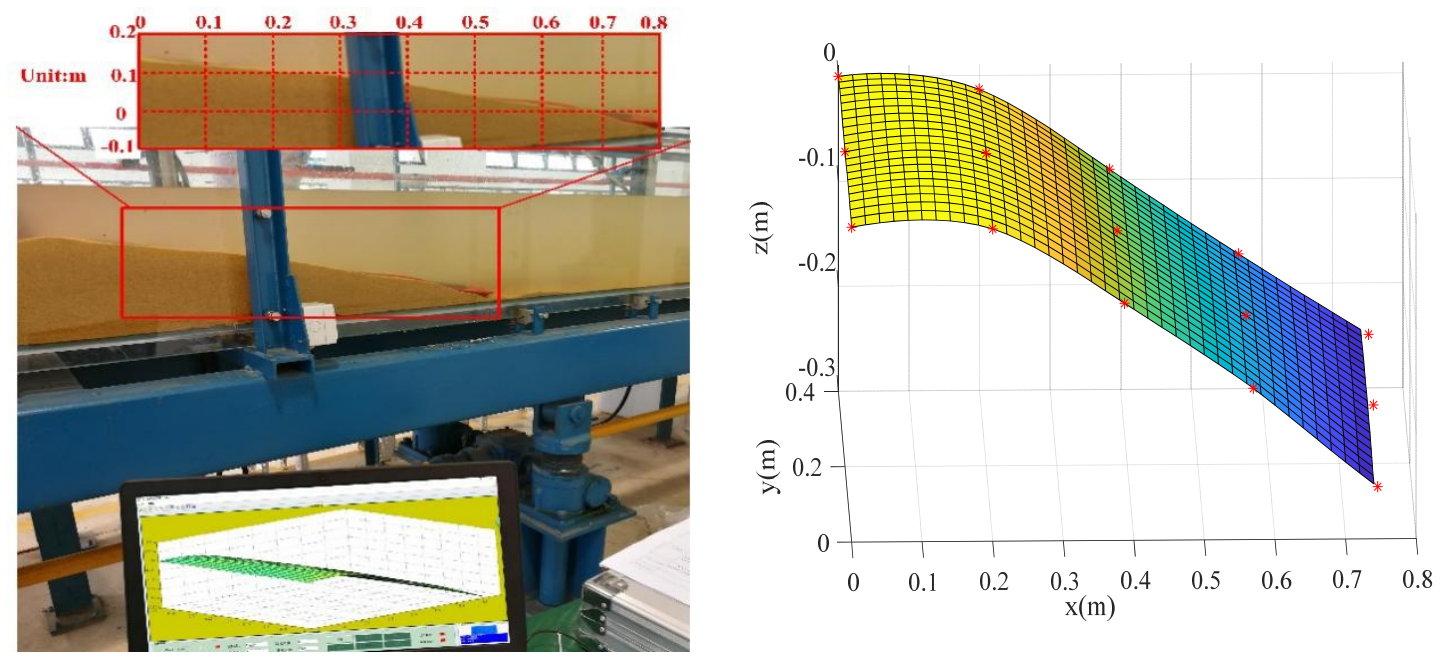

Figure 22. Shape \#2-5. Sand bed (left), reconstruction graph (right). 
Table 4. Measurement error statistics.

\begin{tabular}{cccccc}
\hline & Shape \#2-1 & Shape \#2-2 & Shape \#2-3 & Shape \#2-4 & Shape \#2-5 \\
\hline MRE (\%) & 3.29 & 5.62 & 3.36 & 5.71 & 3.48 \\
RRMSE $(\%)$ & 3.52 & 5.89 & 3.45 & 6.73 & 3.02 \\
\hline
\end{tabular}

Table 4 shows that the maximum error of the sand beds is Shape \#2-4. The maximum RRMSE and MRE were 6.73 and $5.71 \%$, respectively. Two primary factors caused the errors. First, the angle error obtained by the above-mentioned sensors increased the reconstruction error. Second, the monitoring range of the sand bed was small. Energy loss occurred in the highest frequency calculation and produced a reconstruction error. The small error showed strong agreement between the data obtained by the sensor arrays and real data obtained by the ultrasonic measuring system.

The two-dimensional amplitude spectra of Shapes \#2-4 and \#2-5 were obtained. Similar to Shapes \#21-\#2-3, the main frequency was concentrated in the low-frequency range. The highest frequencies of Shapes \#2-4 and \#2-5 were $R=\max \{\xi, \eta\}=2.5 \mathrm{~m}^{-1}$ and satisfy the sampling theorem. The results showed that the arc-length interval between the sensors can be determined according to the two-dimensional non-uniform sampling condition.

\section{Conclusions}

This article presented a sensor placement strategy with two-dimensional equal arc length non-uniform sampling for underwater terrain deformation monitoring and a mathematical model of two-dimensional uniform sampling. The two-dimensional non-uniform spatial sampling with equal arc length condition was derived from the frame theorem. The number of sensors and arc length interval of the sensors were determined by the non-uniform sampling condition. Terrain deformation and water tank tests were conducted using an MEMS accelerometer network, and the experimental results showed the correctness of the two-dimensional non-uniform sampling condition with equal arc length. The research results guide the placement of sensors on the sensor array in submarine terrain monitoring and reconstructing, and can also be extended to other areas of shape monitoring and reconstruction based on the sensor array. The principal conclusions are the following:

(1) According to the two-dimensional non-uniform sampling theorem, the arc length interval of the sensors should be less than $\frac{1}{2 \Omega}$ in order to completely reconstruct the underwater terrain.

(2) A strong agreement was demonstrated between the MEMS accelerometer sensor array data and the terrain data. The maximum MRE and the maximum RMSE were both less than seven percent in the terrain deformation simulation and the water tank experiments.

(3) The monitoring range for application is limited, the frequency spectrum is infinite. Additionally, and the highest frequency calculation leads to energy loss. Therefore, although the condition of the arc length interval is satisfied, the reconstruction error is not close to zero. Thus, the sensor interval should be shortened to reduce the reconstruction error. A greater number of sensors produces shorter sensor intervals and lower reconstruction errors.

(4) In practical application, because it is difficult to obtain reliable and high-precision terrain data, the number and the interval of the sensors are also hard to calculated. Therefore, the two-dimension arc non-uniform sampling model must be used with highprecision submarine terrain detection instruments (such as high precision multi-beam echo sounding).

Author Contributions: Conceptualization, C.X. and J.H.; Formal analysis, C.X., J.H. and Y.G.; Funding acquisition, C.X. and J.C.; Investigation, Y.G.; Methodology, C.X., J.H., J.C. and Y.G.; Project administration, J.C.; Supervision, J.C.; Visualization, C.X.; Writing—original draft, C.X.; Writingreview and editing, R.L. All authors have read and agreed to the published version of the manuscript. 
Funding: This research was funded by National Natural Science Foundation of China, grant number, 42106205 and 41976055; Guangdong Basic and Applied Basic Research Foundation, grant number 2019A1515110372 and 2021A1515011475; the STU Scientific Research Foundation for Talents, grant number, NTF19034.

Institutional Review Board Statement: Not applicable.

Informed Consent Statement: Not applicable.

Data Availability Statement: Not applicable.

Conflicts of Interest: The authors declare no conflict of interest.

\section{References}

1. Wang, Z.; Jia, Y.; Liu, X.; Wang, D.; Shan, H.; Guo, L.; Wei, W. In situ observation of storm-wave-induced seabed deformation with a submarine landslide monitoring system. Bull. Eng. Geol. Environ. 2018, 77, 1091-1102. [CrossRef]

2. Putti, S.P.; Satyam, N. Evaluation of Site Effects Using HVSR Microtremor Measurements in Vishakhapatnam (India). Earth Syst. Environ. 2020, 4, 439-454. [CrossRef]

3. Shi, Y.H.; Liang, Q.Y.; Yang, J.P.; Yuan, Q.M.; Kong, L. Stability analysis of submarine slopes in the area of the test production of gas hydrate in the south china sea. China Geol. 2019, 2, 276-286. [CrossRef]

4. Vanneste, M.; Sultan, N.; Garziglia, S.; Forsberg, C.F.; L'Heureux, J.S. Seafloor instabilities and sediment deformation processes: The need for integrated, multi-disciplinary investigations. Mar. Geol. 2014, 352, 183-214. [CrossRef]

5. Amiri-Simkooei, A.R.; Snellen, M.; Simons, D.G. Principal component analysis of single-beam echo-sounder signal features for seafloor classification. IEEE J. Ocean. Eng. 2011, 36, 259-272. [CrossRef]

6. Hefner, B.T. Characterization of seafloor roughness to support modeling of midfrequency reverberation. IEEE J. Ocean. Eng. 2017, 42, 1110-1124. [CrossRef]

7. Calvert, J.; Strong, J.A.; Service, M.; McGonigle, C.; Quinn, R. An evaluation of supervised and unsupervised classification techniques for marine benthic habitat mapping using multibeam echosounder data. ICES J. Mar. Sci. 2015, 72, 1498-1513. [CrossRef]

8. Holler, P.; Markert, E.; Bartholom, A.; Capperucci, R.; Reimers, H.C. Tools to evaluate seafloor integrity: Comparison of multidevice acoustic seafloor classifications for benthic macrofauna-driven patterns in the german bight, southern north sea. Geo-Mar. Lett. 2016, 37, 1-17. [CrossRef]

9. Lamarche, G.; Lurton, X. Recommendations for improved and coherent acquisition and processing of backscatter data from seafloor-mapping sonars. Mar. Geophys. Res. 2018, 39, 5-22. [CrossRef]

10. Zhu, H.H.; Shi, B.; Yan, J.F.; Zhang, J.; Wang, B.J. Fiber bragg grating-based performance monitoring of a slope model subjected to seepage. Smart Mater. Struct. 2014, 23, 1-12. [CrossRef]

11. Moe, A.; Aminossadati, S.M.; Kizil, M.S.; Rakić, A.D. Recent developments in fibre optic shape sensing. Measurement 2018, 128, 119-137.

12. Hauswirth, D.; Puzrin, A.M.; Carrera, A.; Standing, J.R.; Wan, M.S.P. Use of fibre-optic sensors for simple assessment of ground surface displacements during tunneling. Geothchnique 2014, 64, 837-842. [CrossRef]

13. Zhang, Y.; Tang, H.; Li, C.; Lu, G.; Cai, Y.; Zhang, J.; Tan, F. Design and testing of a flexible inclinometer probe for model tests of landslide deep displacement measurement. Sensors 2018, 18, 224. [CrossRef] [PubMed]

14. Xu, C.; Chen, J.; Zhu, H.; Liu, H.; Lin, Y. Experimental research on seafloor mapping and vertical deformation monitoring for gas hydrate zone using nine-axis MEMS sensor tapes. IEEE J. Ocean. Eng. 2018, 44, 1090-1101. [CrossRef]

15. Xu, C.; Chen, J.; Ge, Y.; Ren, Z.; Cao, C.; Zhu, H.; Huang, Y.; Wang, H.; Wang, W. Monitoring the vertical changes of a tidal flat using a mems accelerometer array. Appl. Ocean. Res. 2020, 101, 102186. [CrossRef]

16. Leal-Junior, A.G.; Frizera-Neto, A.; Pontes, M.J.; Botelho, T.R. Hysteresis compensation technique applied to polymer optical fiber curvature sensor for lower limb exoskeletons. Meas. Sci. Technol. 2017, 28, 125103. [CrossRef]

17. Leal-Junior, A.G.; Anselmo, F.; Avellar, L.M.; Pontes, M.J. Design considerations, analysis, and application of a low-cost, fully portable, wearable polymer optical fiber curvature sensor. Appl. Opt. 2018, 57, 6927-6936. [CrossRef]

18. Gong, H.; Xiao, Y.; Kai, N.; Zhao, C.L.; Dong, X. An optical fiber curvature sensor based on two peanut-shape structures modal interferometer. IEEE Photonic Technol. Lett. 2013, 26, 22-24. [CrossRef]

19. De Kim, T.; Youn, B.D.; Oh, H. Development of a stochastic effective independence (sefi) method for optimal sensor placement under uncertainty. Mech. Syst. Signal Process. 2018, 111, 615-627. [CrossRef]

20. Kang, L.; Ren-Jun, Y.; Guedes, S.C. Optimal sensor placement and assessment for modal identification. Ocean Eng. 2018, 165, 209-220.

21. Ameyaw, D.A.; Rothe, S.; Söffker, D. Fault diagnosis using probability of detection (pod)-based sensor/information fusion for vibration-based analysis of elastic structures. PAMM 2018, 18, 1-2. [CrossRef]

22. Tong, K.H.; Bakhary, N.; Kueh, A.; Yassin, A. Optimal sensor placement for mode shapes using improved simulated annealing. Smart Struct. Syst. 2014, 13, 389-406. [CrossRef] 
23. Gomes, G.F.; Almeida, F.D.; Alexandrino, P.L. A multiobjective sensor placement optimization for SHM systems considering fisher information matrix and mode shape interpolation. Eng. Comput.-Ger. 2019, 35, 519-535. [CrossRef]

24. Downey, A.; Hu, C.; Laflamme, S. Optimal sensor placement within a hybrid dense sensor network using an adaptive genetic algorithm with learning gene pool. Struct. Health Monit. 2017, 17, 450-460. [CrossRef]

25. Marks, R.; Clarke, A.; Featherston, C.A.; Pullin, R. Optimization of acousto-ultrasonic sensor networks using genetic algorithms based on experimental and numerical data sets. Int. J. Distrib. Sens. Netw. 2017, 13. [CrossRef]

26. Huang, Y.; Ludwig, S.A.; Deng, F. Sensor optimization using a genetic algorithm for structural health monitoring in harsh environments. J. Civ. Struct. Health Monit. 2016, 6, 509-519. [CrossRef]

27. Long, D.G.; Franz, R. Band-Limited signal reconstruction from irregular samples with variable apertures. IEEE Trans. Geosci. Remote 2016, 54, 2424-2436. [CrossRef]

28. Hu, Y.; Fan, Y.; Wei, Y.; Wang, Y.; Liang, Q. Subspace-based continuous-time identification of fractional order systems from non-uniformly sampled data. Int. J. Sys. Sci. 2016, 47, 122-134. [CrossRef]

29. Souglo, K.E. Non-uniform distributions of initial porosity in metallic materials affect the growth rate of necking instabilities in flat tensile samples subjected to dynamic loading. Mech. Res. Commun. 2018, 91, 87-92.

30. Zhao, S.; Wang, R.; Deng, Y.; Zhang, Z.; Li, N.; Guo, L.; Wang, W. Modifications on multichannel reconstruction algorithm for SAR processing based on periodic nonuniform sampling theory and nonuniform fast fourier transform. IEEE J. Sel. Top. Appl. Earth Obs. Remote. Sens. 2015, 8, 4998-5006. [CrossRef]

31. Marvasti, F. Nonuniform Sampling: Theory and Practice; Kluwer Academic: Dordrecht, The Netherlands, 2001.

32. Haykin, S.; Barry, V.V. Signals and Systems, 2nd ed.; Wiley: Hoboken, NJ, USA, 2003. 